\title{
Modeling and Control of Magnetorheological Dampers for Seismic Response Reduction
}

\author{
S.J. Dyke, ${ }^{1}$ B.F. Spencer Jr., ${ }^{2}$ M.K. Sain ${ }^{3}$ and J.D. Carlson ${ }^{4}$ \\ ${ }^{1}$ Dept. of Civil Engrg., Washington University, St. Louis, MO 63130 \\ ${ }^{2}$ Dept. of Civil Engrg. and Geo. Sci., Univ. of Notre Dame, Notre Dame, IN 46556 \\ ${ }^{3}$ Dept. of Electrical Engrg., Univ. of Notre Dame, Notre Dame, IN 46556 \\ ${ }^{4}$ Mechanical Products Division, Lord Corporation, Cary, NC 27511
}

\begin{abstract}
Control of civil engineering structures for earthquake hazard mitigation represents a relatively new area of research that is growing rapidly. Control systems for these structures have unique requirements and constraints. For example, during a severe seismic event, the external power to a structure may be severed, rendering control schemes relying on large external power supplies ineffective. Magnetorheological (MR) dampers are a new class of devices that mesh well with the requirements and constraints of seismic applications, including having very low power requirements. This paper proposes a clipped-optimal control strategy based on acceleration feedback for controlling MR dampers to reduce structural responses due to seismic loads. A numerical example, employing a newly developed model that accurately portrays the salient characteristics of the MR dampers, is presented to illustrate the effectiveness of the approach.
\end{abstract}

\section{Introduction}

The tragic consequences of the recent earthquakes in Kobe, Japan and in Los Angeles, California have underscored, in terms of both human and economic factors, the tremendous importance of the way in which buildings and bridges respond to earthquakes. In the last decade, significant effort has been devoted to the possibility of employing various control strategies in the design of engineering structures to increase their safety and reliability against strong earthquakes $[20,22-24,39]$. These control approaches are often termed protective systems and offer the advantage of being able to modify dynamically the response of a structure in a desirable manner. Moreover, structural control systems can be an effective means by which existing structures can be retrofitted or strengthened to withstand future seismic activity.

To date, active structural control has been successfully applied in over twenty commercial buildings and more than ten bridges (during erection) [20]. Yet there are a number of serious challenges that remain before active control can gain general acceptance by the engineering and construction professions at large. These challenges include: (i) reduction of capital cost and maintenance, (ii) eliminating reliance on external power, (iii) increasing system reliability and robustness, and (iv) gaining acceptance of nontraditional technology by the profession. Semi-active 
control strategies appear to be particularly promising in addressing a number of these challenges [43].

Semi-active control devices potentially offer the reliability of passive devices, yet maintain the versatility and adaptability of fully active systems. According to presently accepted definitions, a semi-active control device is one which cannot input energy into the system being controlled. Such devices typically have extremely low power requirements, which is particularly critical during seismic events when the main power source to the structure may fail.

Various semi-active devices have been proposed which utilize forces generated by surface friction or viscous/viscoelastic-plastic fluids to dissipate vibratory energy in a structural system. Examples of such devices that have been considered for civil engineering applications include: variable orifice dampers [9, 26, 29, 34, 36, 38], controllable friction braces [1, 10], controllable friction isolators [19], variable stiffness devices [27], and electrorheological (ER) dampers [2, 17, $18,21,30,32]$. The effectiveness of one semi-active control system employing a variable stiffness system has already been proven in a low-rise building in Japan [28].

Magnetorheological (MR) dampers are new semi-active control devices that use MR fluids to provide controllable dampers that are quite promising for civil engineering applications [8, 15, 42]. They offer highly reliable operation at a modest cost and can be viewed as fail-safe in that they become passive dampers should the control hardware malfunction. This paper first presents a recently developed model for a prototype MR damper [42] that has been studied in the Structural Dynamics and Control / Earthquake Engineering Laboratory (http://www.nd.edu/ quake/) at the University of Notre Dame. Then a clipped-optimal acceleration feedback control strategy is proposed for controlling the MR damper. The effectiveness of the proposed algorithm and the usefulness of MR dampers for structural response reduction are demonstrated through a numerical example employing a seismically excited three story model building.

\section{MR Damper Behavior and Modeling}

Magnetorheological fluids recently developed by the Lord Corporation [3-7] (see also http:// www.rheonetic.com/mrfluid/) have many attractive features, including high yield strength, low viscosity and stable hysteretic behavior over a broad temperature range. MR fluids are the magnetic analogs of electrorheological (ER) fluids and typically consist of micron-sized, magnetically polarizable particles dispersed in a carrier medium such as mineral or silicone oil. When a magnetic field is applied to the fluids, particle chains form, and the fluid becomes a semi-solid, exhibiting plastic behavior similar to that of ER fluids. Transition to rheological equilibrium can be achieved in a few milliseconds, providing devices with high bandwidth. Additionally, the achievable yield stress of modern MR fluids is in excess of $80 \mathrm{kPa}$, allowing for devices capable of generating large forces such as are required for full-scale installations. In fact, MR dampers with a capacity of 20 tons have been designed, with testing to begin in the summer of 1996 [8]. Moreover, MR fluids can operate at temperatures from -40 to $150^{\circ} \mathrm{C}$ with only slight variations in the yield stress. Consequently, devices based on MR fluids are viable candidates for installation in both exterior civil infrastructure applications (e.g., bridges, towers, etc.) as well as enclosed applications (e.g., buildings, secondary systems, etc.).

To evaluate the potential of MR dampers in structural control applications and to take full advantage of the unique features of these devices, a model must be developed that can accurately reproduce the behavior of the MR damper. A prototype MR damper has been considered, which was obtained for evaluation from the Lord Corporation and is comprised of a fixed orifice damper 


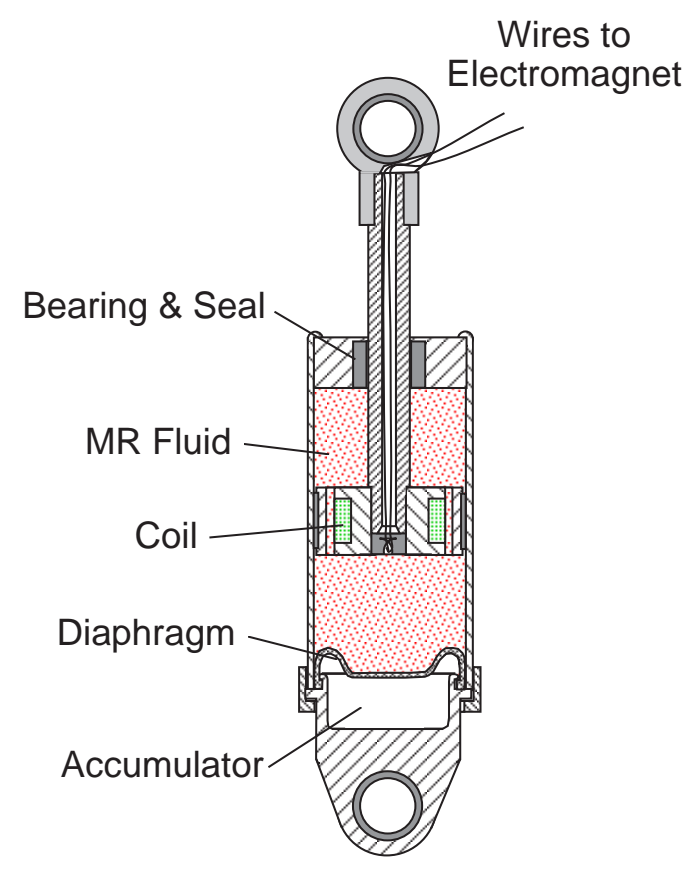

Figure 1. Schematic of MR Damper.

filled with an MR fluid [42]. The damper is $21.5 \mathrm{~cm}$ long in its extended position, and the main cylinder is $3.8 \mathrm{~cm}$ in diameter. The main cylinder houses the piston, the magnetic circuit, an accumulator and $50 \mathrm{ml}$ of MR fluid, and the damper has a $\pm 2.5 \mathrm{~cm}$ stroke. As shown in Fig. 1, the magnetic field produced in the device is generated by a small electromagnet in the piston head. The current for the electromagnet is supplied by a linear current driver running off of $120 \mathrm{~V} \mathrm{AC}$, which generates a $0-1$ amp current that is proportional to an applied DC input voltage in the range 0-3 V. The peak power required is less than 10 watts, which could allow the damper to be operated continuously for more than an hour on a small camera battery. Forces of up to $3000 \mathrm{~N}$ can be generated with the device. The force is stable over a broad temperature range, varying less than $10 \%$ in the range of -40 to 150 degrees Celsius. The rise time (defined as the time required to go from $10 \%$ to $90 \%$ of the final value) in the force generated by the MR damper during a constant velocity test when a step in the voltage is applied to the current driver is approximately $8 \mathrm{msec}$. This behavior is primarily due to the time the MR fluid in the damper takes to reach rheological equilibrium and the time lag associated with the dynamics of driving the electromagnet in the MR damper.

The response of the MR damper due to a $2.5 \mathrm{~Hz}$ sinusoid with an amplitude of $1.5 \mathrm{~cm}$ is shown in Fig. 2 for four constant voltage levels, $0 \mathrm{~V}, 0.75 \mathrm{~V}, 1.5 \mathrm{~V}$, and $2.25 \mathrm{~V}$, being applied to the current driver for the device. These voltages correspond to $0 \mathrm{~A}, 0.25 \mathrm{~A}, 0.5 \mathrm{~A}$ and $0.75 \mathrm{~A}$, respectively. Saturation of the MR effect begins in the tested device when the applied voltage is 2.25 $\mathrm{V}(0.75 \mathrm{~A})$. Thus, attention is restricted to voltages between 0 and $2.25 \mathrm{~V}$. The measured forces are shown as a function of time in Fig. 2a, the force-displacement loops are shown in Fig. 2b, and the force-velocity loops are shown in Fig. 2c. The force-displacement loops in Fig. 2b progress along a clockwise path with increasing time, whereas the force-velocity loops in Fig. 2c progress along a counter-clockwise path with increasing time. Note that the nonzero mean force produced by the MR damper is due to the accumulator (see Fig. 1). 
In Fig. 2, the effects of changing the magnetic field are readily observed. At $0 \mathrm{~V}$ the MR damper primarily exhibits the characteristics of a viscous device (i.e., the force-displacement relationship is approximately elliptical, and the force-velocity relationship is nearly linear). However, as the voltage increases, the force required to yield the fluid increases and produces behavior associated with a plastic material in parallel with a viscous damper, i.e., Bingham plastic behavior [37].

The simple mechanical idealizations of the MR damper depicted in Fig. 3 has been shown to accurately predict the behavior of the prototype MR damper over a broad range of inputs [42]. The applied force $f$ predicted by this model is given by

$$
f=\alpha z+c_{0}(\dot{x}-\dot{y})+k_{0}(x-y)+k_{1}\left(x-x_{0}\right)
$$

or equivalently

$$
f=c_{1} \dot{y}+k_{1}\left(x-x_{0}\right)
$$

where the evolutionary variable $z$ is governed by [45]

$$
\dot{z}=-\gamma|\dot{x}-\dot{y}| z|z|^{n-1}-\beta(\dot{x}-\dot{y})|z|^{n}+A(\dot{x}-\dot{y})
$$

and

$$
\dot{y}=\frac{1}{\left(c_{0}+c_{1}\right)}\left\{\alpha z+c_{0} \dot{x}+k_{0}(x-y)\right\}
$$

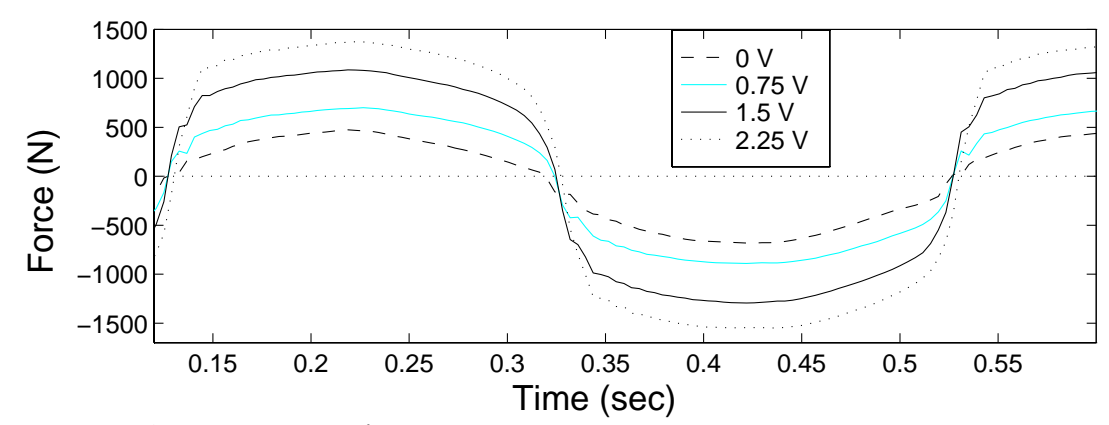

a) Force vs. Time

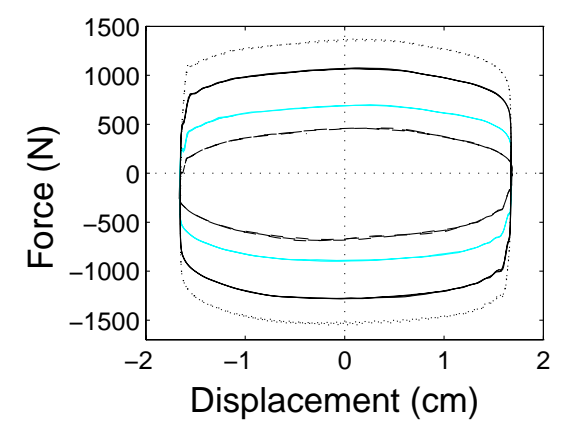

b) Force vs. Displacement

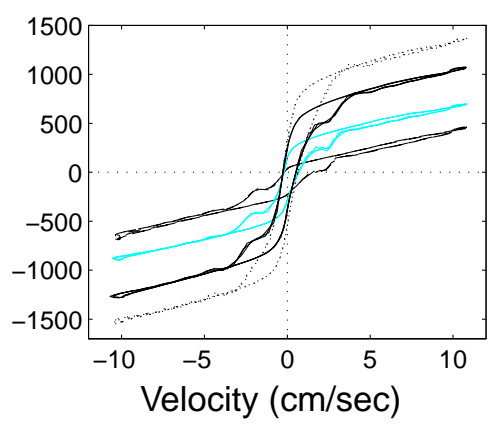

c) Force vs. Velocity

Figure 2. Experimentally Measured Force for $2.5 \mathrm{~Hz}$ Sinusoidal Excitation with an Amplitude of $1.5 \mathrm{~cm}$. 
Here, the accumulator stiffness is represented by $k_{1}$, the viscous damping observed at larger velocities by $c_{0}$. A dashpot, represented by $c_{1}$, is included in the model to introduce the nonlinear roll-off in the force-velocity loops that was observed in the experimental data at low velocities, $k_{0}$ is present to control the stiffness at large velocities, and $x_{0}$ is the initial displacement of spring $k_{1}$ associated with the nominal damper force due to the accumulator. By adjusting the parameters of the model $\gamma, \beta$ and $A$, one can control the shape of the hysteresis loops for the yielding element.

To account for the dependence of the force on the voltage applied to the current driver and the resulting magnetic current, Spencer, et al. [42] have suggested

$$
\begin{gathered}
\alpha=\alpha(u)=\alpha_{a}+\alpha_{b} u \\
c_{1}=c_{1}(u)=c_{1 a}+c_{1 b} u \\
c_{0}=c_{0}(u)=c_{0 a}+c_{0 b} u
\end{gathered}
$$

where $u$ is given as the output of a first-order filter given by

$$
\dot{u}=-\eta(u-v)
$$

and $v$ is the commanded voltage sent to the current driver. Eq. (8) is necessary to model the dynamics involved in reaching rheological equilibrium and in driving the electromagnet in the MR damper.

A constrained nonlinear optimization was used to obtain the 14 model parameters in Eqs. (18). The optimization was performed using the sequential quadratic programming algorithm available in MATLAB [31]. Optimized parameters were determined to fit the generalized model to the experimental data in a variety of tests. The resulting parameters are given in Table 1.

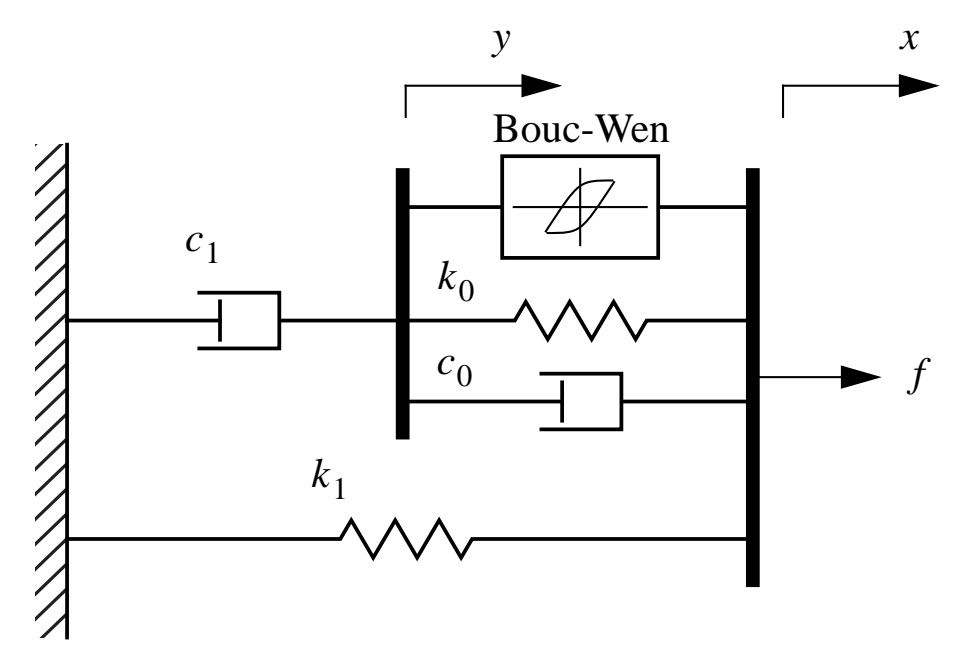

Figure 3. Simple Mechanical Model of the MR Damper. 
Table 1: Parameters for the MR Damper Model

\begin{tabular}{|c|c||c|c|}
\hline Parameter & Value & Parameter & Value \\
\hline \hline$c_{0 a}$ & $21.0 \mathrm{~N} \cdot \mathrm{sec} / \mathrm{cm}$ & $\alpha_{a}$ & $140 \mathrm{~N} / \mathrm{cm}$ \\
\hline$c_{0 b}$ & $3.50 \mathrm{~N} \cdot \mathrm{sec} / \mathrm{cm} \cdot \mathrm{V}$ & $\alpha_{b}$ & $695 \mathrm{~N} / \mathrm{cm} \cdot \mathrm{V}$ \\
\hline$k_{0}$ & $46.9 \mathrm{~N} / \mathrm{cm}$ & $\gamma$ & $363 \mathrm{~cm}^{-2}$ \\
\hline$c_{1 a}$ & $283 \mathrm{~N} \cdot \mathrm{sec} / \mathrm{cm}$ & $\beta$ & $363 \mathrm{~cm}^{-2}$ \\
\hline$c_{1 b}$ & $2.95 \mathrm{~N} \cdot \mathrm{sec} / \mathrm{cm} \cdot \mathrm{V}$ & $A$ & 301 \\
\hline$k_{1}$ & $5.00 \mathrm{~N} / \mathrm{cm}$ & $n$ & 2 \\
\hline$x_{0}$ & $14.3 \mathrm{~cm}$ & $\eta$ & $190 \mathrm{sec}^{-1}$ \\
\hline
\end{tabular}

To illustrate the validity of this model, a random displacement and a random voltage were applied to the MR damper simultaneously, and the results compared with those predicted by the model. Here, the displacement was chosen to be a narrow-band Gaussian excitation representative of the response of a scaled model structure, and the voltage to the current driver was prescribed as a binary noise with a value of either $0 \mathrm{~V}$ or $2.25 \mathrm{~V}$ (Fig. 4). Figure 5 shows a comparison between the experimental and predicted behavior of the damper. Excellent agreement is found between the force predicted by the model and the experimentally measured forces. Therefore, the model given in Eqs. (1)-(8) and the parameters given Table 1 will be employed in the subsequent sections to demonstrate the potential of the use of MR technology for seismic response reduction.

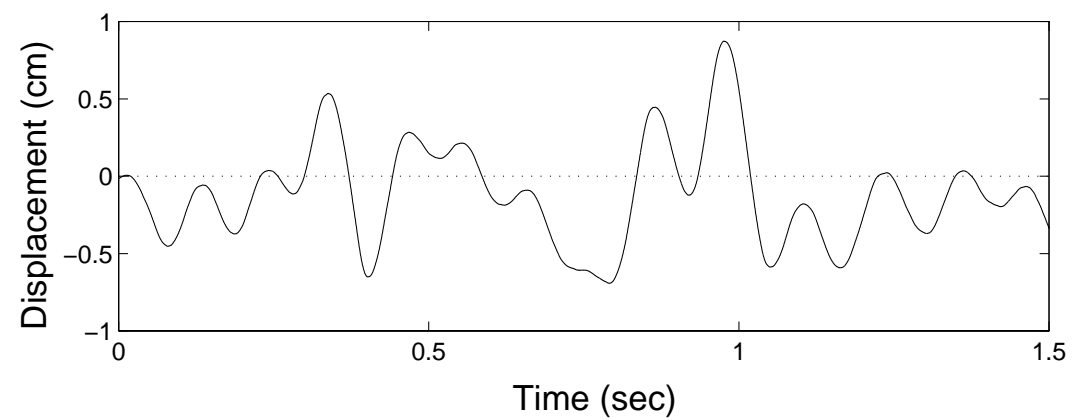

a) Displacement vs. Time

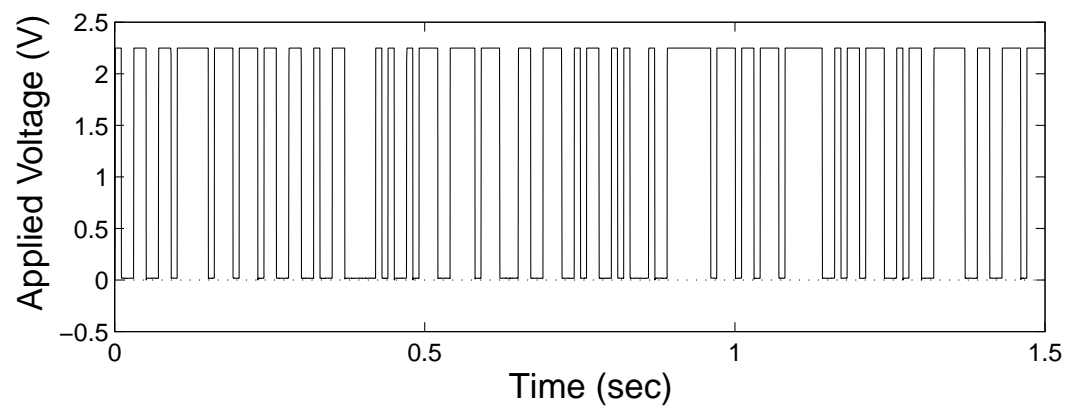

b) Applied Voltage vs. Time

Figure 4. Inputs to MR Damper During the Random Displacement, Random Voltage Test. 


\section{Clipped-Optimal Control Algorithm Development}

Previous researchers have found semi-active control systems can potentially achieve the majority of the performance of fully active systems [25, 33, 35, 44]. Because semi-active control devices are inherently stable (in a bounded input - bounded output sense), high authority control strategies may be designed and implemented, which, in practice, may result in performances that can even surpass that of an actively controlled structure.

In this study, a type of clipped-optimal controller [35, 44] based on acceleration feedback is proposed. To date, most of the current active structural control strategies for aseismic protection have been based on either full-state feedback (i.e., all structural displacements and velocities) or on velocity feedback. However, accurate measurement of displacements and velocities is difficult to achieve directly in full-scale applications, particularly during seismic activity, since the foundation of the structure is moving with the ground. Because accelerometers can readily provide reliable and inexpensive measurement of accelerations at arbitrary points on the structure, development of control methods based on acceleration feedback is an ideal solution to this problem and will be presented subsequently.

Consider a seismically excited structure controlled with a single MR damper. Assuming that the forces provided by the MR damper are adequate to keep the response of the primary structure from exiting the linear region, then the equations of motion can be written as

$$
\dot{\mathbf{z}}=\mathbf{A} \mathbf{z}+\mathbf{B} f+\mathbf{E} \ddot{x}_{g}
$$

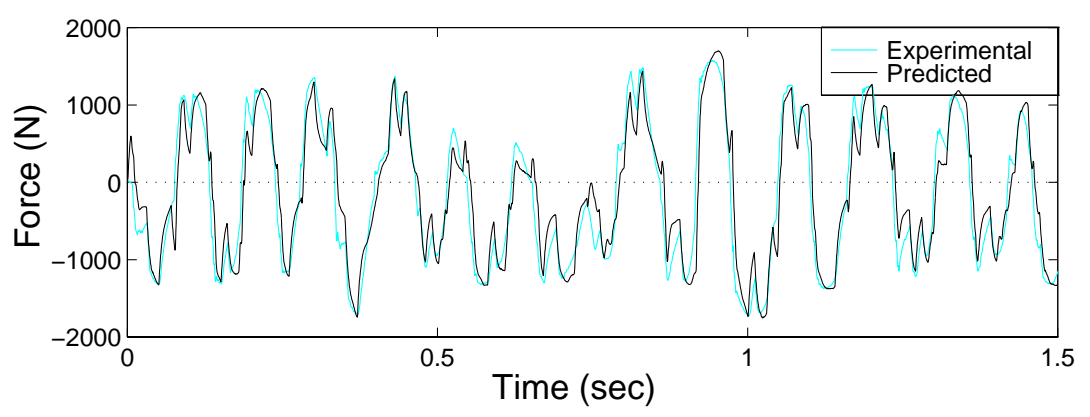

a) Force vs. Time

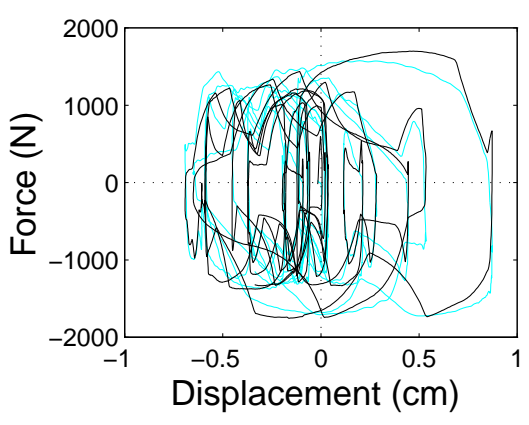

b) Force vs. Displacement

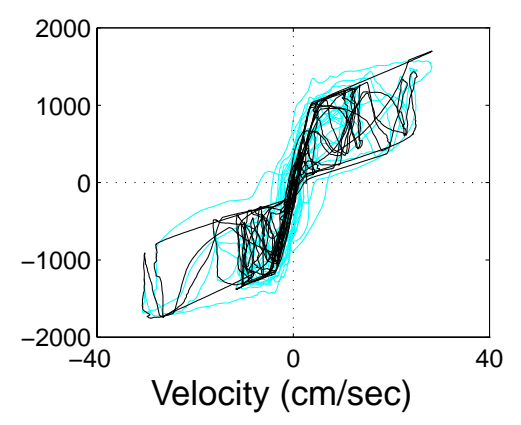

c) Force vs. Velocity

Figure 5. Comparison of the Model Results and the Experimental Data for the Random Displacement, Random Voltage Test. 
where $\ddot{x}_{g}$ is a one-dimensional ground acceleration, $f$ is the measured force generated between the structure and the MR damper (e.g., Eq. (1) or (2)), and $\mathbf{z}$ is the state vector. The measurement equation is given by

$$
\mathbf{y}=\mathbf{C z}+\mathbf{D} f+\mathbf{v}
$$

where $\mathbf{y}$ is the vector of measured outputs, and $\mathbf{v}$ is the measurement noise vector. In this application, the measurements typically available for control force determination include the acceleration of selected points on the structure, the displacement $x$ of the MR damper and the measurement of the control force $f$ provided by the MR damper.

The approach proposed here is to append a force feedback loop [25] to induce the MR damper to produce approximately a desired control force $f_{c}$. A linear optimal controller $\mathbf{K}_{c}(s)$ is then designed that provides the desired control force $f_{c}$ based on the measured responses $\mathbf{y}$, and the measured force $f$, i.e.,

$$
f_{c}=\mathcal{L}^{-1}\left\{-\mathbf{K}_{c}(s) \mathcal{L}\left(\left[\begin{array}{l}
\mathbf{y} \\
f
\end{array}\right]\right)\right\}
$$

where $\mathcal{L}\{\cdot\}$ is the Laplace transform. Although the controller $\mathbf{K}_{c}(s)$ can be obtained from a variety of synthesis methods, the $\mathrm{H}_{2} / \mathrm{LQG}$ strategies are advocated herein because of the stochastic nature of earthquake ground motions and because of their successful application in other civil engineering structural control applications [12, 13, 13, 40, 41].

The force generated by the MR damper cannot be commanded; only the voltage $v$ applied to the current driver for the MR damper can be directly changed. To induce the MR damper to generate approximately the desired optimal control force $f_{c}$, the command signal $v$ is selected as follows. When the MR damper is providing the desired optimal force (i.e., $f=f_{c}$ ), the voltage applied to the damper should remain at the present level. If the magnitude of the force produced by the damper is smaller than the magnitude of the desired optimal force and the two forces have the same sign, the voltage applied to the current driver is increased to the maximum level so as to increase the force produced by the damper to match the desired control force. Otherwise, the commanded voltage is set to zero. The algorithm for selecting the command signal is graphically represented in Fig. 6 and can be concisely stated as

$$
v=V_{\max } H\left\{\left(f_{c}-f\right) f\right\}
$$

where $V_{\max }$ is the voltage to the current driver associated with saturation of the magnetic field in the MR damper, and $H(\cdot)$ is the Heaviside step function. A block diagram of this semi-active control system is shown in Fig. 7.

\section{Numerical Example}

The performance of the clipped-optimal control algorithm presented in the previous section is now evaluated through numerical simulation. A model of a three-story building configured with a single MR damper is considered. The MR damper is rigidly connected between the ground and the first floor of the structure. A diagram of the MR damper implementation is shown in Fig. 8. The equations of motion of the structure are given by 


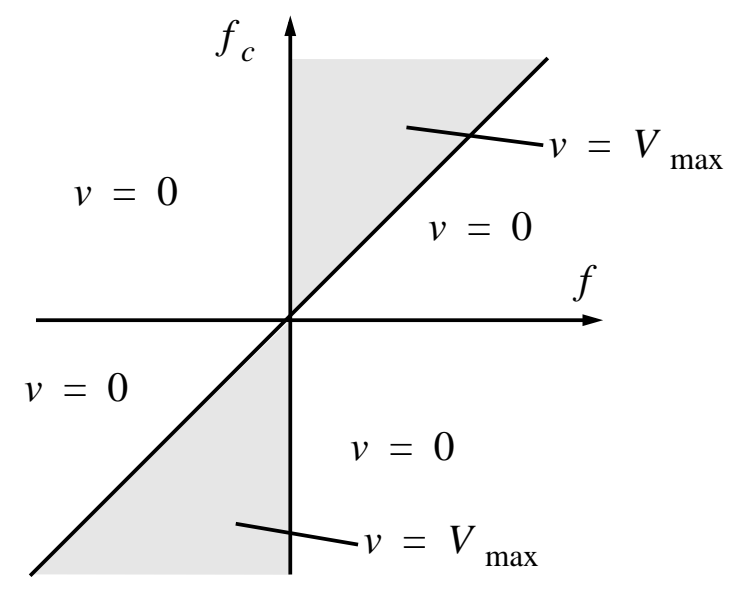

Figure 6. Graphical Representation of Algorithm (i.e., Eq. 12) for Selecting the Command Signal.

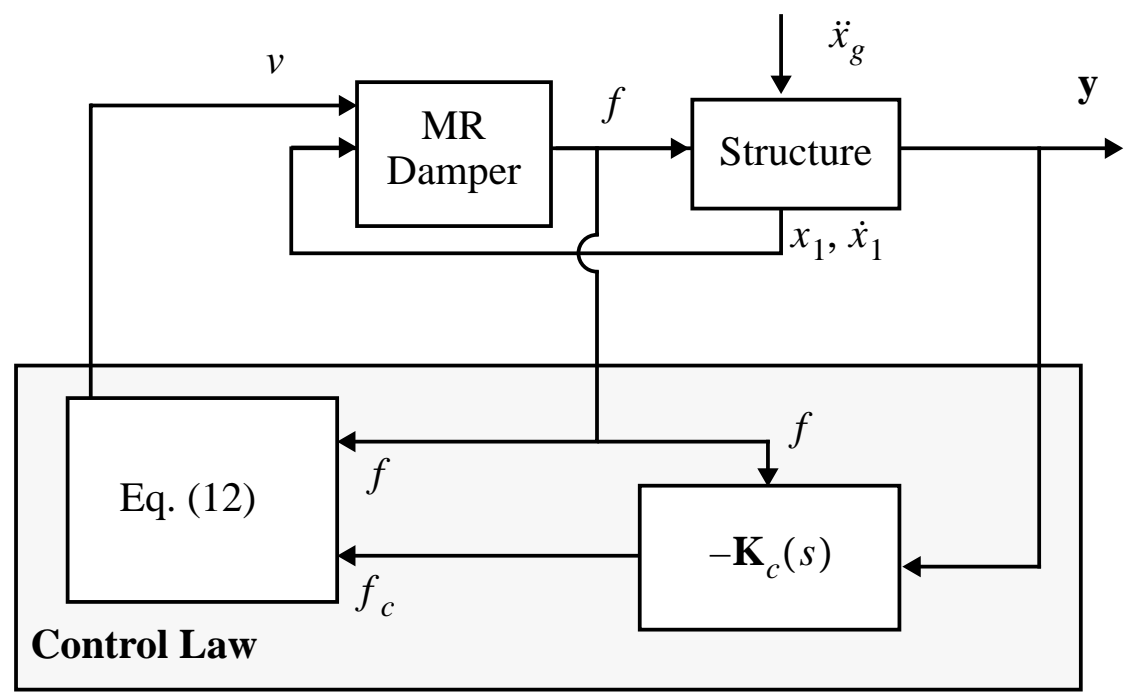

Figure 7. Block Diagram of the Semi-Active Control System.

$$
\mathbf{M}_{s} \ddot{\mathbf{x}}+\mathbf{C}_{s} \dot{\mathbf{x}}+\mathbf{K}_{s} \mathbf{x}=\Gamma f-\mathbf{M}_{s} \Lambda \ddot{x}_{g}
$$

where $f$ is the measured control force, defined by Eqs. (1-8), $\mathbf{x}=\left[\begin{array}{lll}x_{1} & x_{2} & x_{3}\end{array}\right]^{\prime}$ is a vector of the displacements of the three floors of the structure relative to the ground. The system matrices are

$$
\mathbf{M}_{s}=\left[\begin{array}{ccc}
98.3 & 0 & 0 \\
0 & 98.3 & 0 \\
0 & 0 & 98.3
\end{array}\right] \mathrm{kg}, \mathbf{C}_{s}=\left[\begin{array}{ccc}
175 & -50 & 0 \\
-50 & 100 & -50 \\
0 & -50 & 50
\end{array}\right] \frac{\mathrm{N} \cdot \mathrm{sec}}{\mathrm{m}}
$$




$$
\mathbf{K}_{s}=10^{5}\left[\begin{array}{ccc}
12.0 & -6.84 & 0 \\
-6.84 & 13.7 & -6.84 \\
0 & -6.84 & 6.84
\end{array}\right] \frac{\mathrm{N}}{\mathrm{m}}, \Gamma=\left[\begin{array}{c}
-1 \\
0 \\
0
\end{array}\right], \Lambda=\left[\begin{array}{l}
1 \\
1 \\
1
\end{array}\right]
$$

This system is a simple model of the scaled, three-story, test structure, described in [12, 13], which has been used in previous active control studies at the Structural Dynamics and Control / Earthquake Engineering Laboratory (SDC/EEL) at the University of Notre Dame. Because the MR damper is attached between the first floor and the ground, its displacement is equal to the displacement of the first floor of the structure relative to the ground, i.e., $x=x_{1}$ in Eqs. (1-4).

The structural measurements used for calculating the desired control force $f_{c}$ include the absolute accelerations of the three floors of the structure, and the displacement of the MR damper (i.e., $\mathbf{y}=\left[\begin{array}{lllll}\ddot{x}_{a 1} & \ddot{x}_{a 2} & \ddot{x}_{a 3} & x_{1}\end{array}\right]^{\prime}$ ). Thus, Eq. (13) can be written in the form of Eqs. (9-10) by defining

$$
\begin{aligned}
& \mathbf{A}=\left[\begin{array}{cc}
\mathbf{0} & \mathbf{I} \\
-\mathbf{M}_{s}^{-1} \mathbf{K}_{s} & -\mathbf{M}_{s}^{-1} \mathbf{C}_{s}
\end{array}\right], \mathbf{B}=\left[\begin{array}{c}
\mathbf{0} \\
\mathbf{M}_{s}^{-1} \Gamma
\end{array}\right], \mathbf{E}=-\left[\begin{array}{c}
\mathbf{0} \\
\Lambda
\end{array}\right]
\end{aligned}
$$

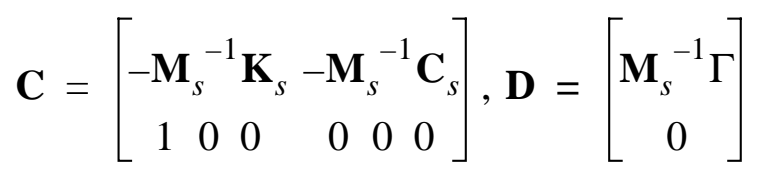

The MR damper parameters given in Table 1 are used for the simulation studies, except that an appropriate translation of coordinates is made to cancel the initial offset caused by the accumulator in the MR damper (i.e., $x_{0}$ was set at zero). The essential effect was to eliminate the need to consider asymmetry in the results.

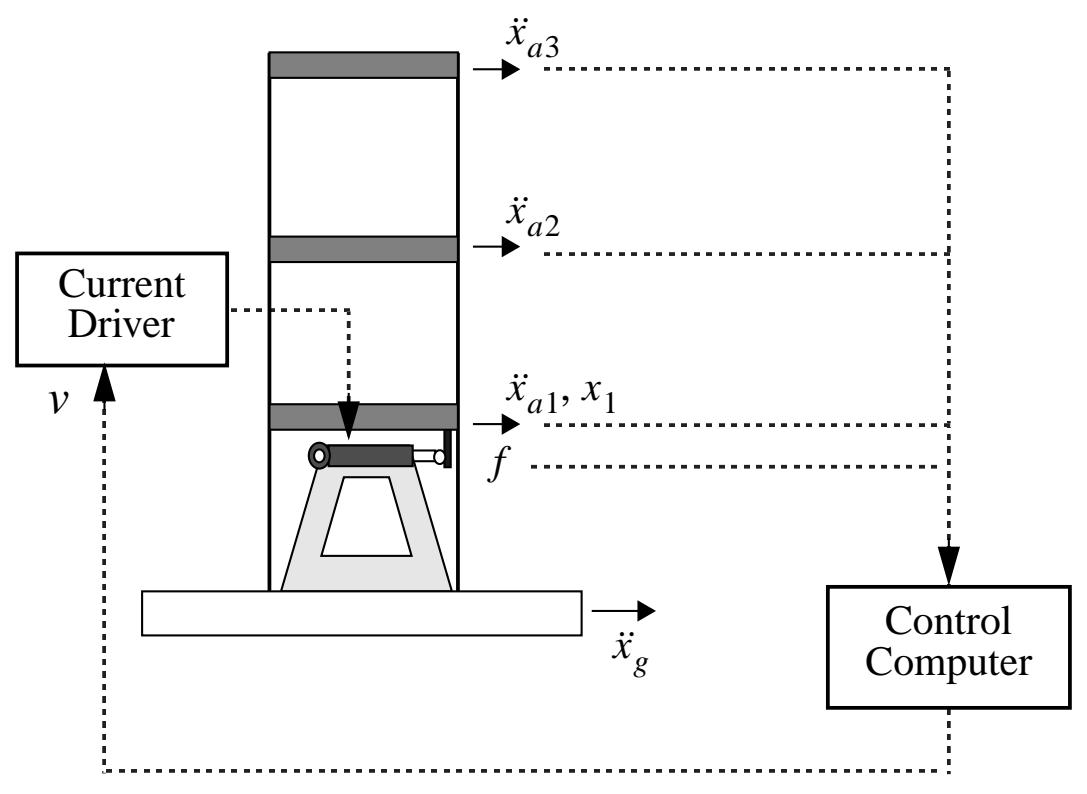

Figure 8. Diagram of MR Damper Implementation. 
Acceleration feedback control strategies based on $\mathrm{H}_{2}$ /LQG methods, developed and experimentally verified in [12-13, 40], are employed to design the optimal controller $\mathbf{K}_{c}(s)$ in Eq. (11) for the system in Eq. (13).

For the control design, the absolute acceleration of the ground, $\ddot{x}_{g}$, is taken to be a stationary white noise, and an infinite horizon performance index is chosen that weights the acceleration of the third floor, i.e.,

$$
J=\lim _{\tau \rightarrow \infty} \frac{1}{\tau} \mathrm{E}\left[\int_{0}^{\tau}\left\{(\mathbf{C z})^{\prime} \mathbf{Q}(\mathbf{C z})+r f_{c}{ }^{2}\right\} d t\right] .
$$

A wide variety of controllers were evaluated. The best results were obtained using $r=10^{-17}$ and choosing all of the elements of the weighting matrix $\mathbf{Q}$ are zero, except for $Q_{33}=1$. Further, the measurement noise is assumed to be identically distributed, statistically independent Gaussian white noise processes, and $S_{\ddot{x}_{g} \ddot{x}_{g}} / S_{v_{i} v_{i}}=\gamma=50$. The controller is

$$
\mathbf{K}_{c}(s)=\mathbf{K}[s \mathbf{I}-(\mathbf{A}-\mathbf{L} \mathbf{C})]^{-1} \hat{\mathbf{B}}
$$

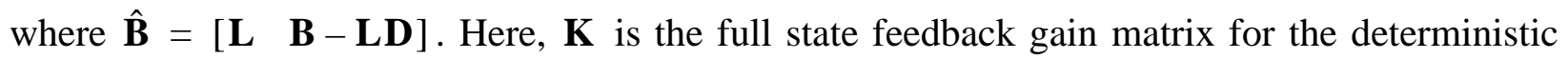
regulator problem given by

$$
\mathbf{K}=\mathbf{B}^{\prime} \mathbf{P} / r
$$

where $\mathbf{P}$ is the solution of the algebraic Ricatti equation given by

$$
\mathbf{0}=\mathbf{P A}+\mathbf{A}^{\prime} \mathbf{P}-\mathbf{P B} \mathbf{B}^{\prime} \mathbf{B P} / r+\mathbf{C}^{\prime} \mathbf{Q} \mathbf{C}
$$

and

$$
\mathbf{L}=(\mathbf{C S})^{\prime}
$$

where $\mathbf{S}$ is the solution of the algebraic Ricatti equation given by

$$
\mathbf{0}=\mathbf{S A}^{\prime}+\mathbf{A S}-\mathbf{S C}^{\prime} \mathbf{C S}+\gamma \mathbf{E} \mathbf{E}^{\prime}
$$

Calculations to determine $\mathbf{K}$ and $\mathbf{L}$ were performed using the control toolbox in MATLAB (1994).

In simulation, the model of the structure is subjected to the NS component of the $1940 \mathrm{El}$ Centro earthquake shown in Fig. 9. Because the system under consideration is a scaled model, the earthquake must be reproduced at five times the recorded rate. The maximum structural responses to the El Centro earthquake are presented in Table 2. Here, $x_{i}$ is the displacement of the $i$ th floor relative to the ground, $d_{i}$ is the interstory drift (i.e., $\left.x_{i}-x_{i-1}\right), \ddot{x}_{a i}$ is the absolute acceleration of the $i$ th floor, and $f$ is the applied control force.

In this study, two cases are considered in which the MR damper is employed in a passive mode. In the first case, designated passive-off, the command voltage to the MR damper is held at $0 \mathrm{~V}$. The second passive case the voltage to the MR damper is held at the maximum voltage level $(2.25 \mathrm{~V})$ and is denoted as passive-on. The results for these two cases indicate that both of the passive systems are able to achieve a reasonable level of performance. As shown in Table 2, the pas- 


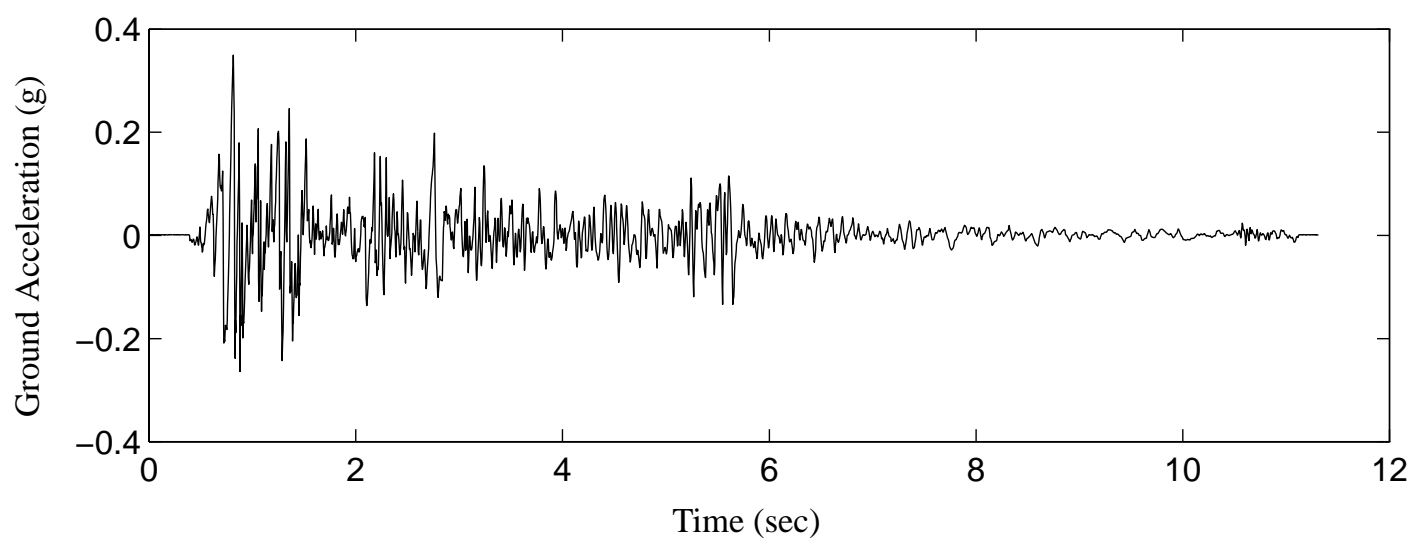

Figure 9. Time Scaled NS Component of the Ground Acceleration for the $1940 \mathrm{El}$ Centro Earthquake.

Table 2: Peak Responses due to the El Centro Earthquake.

\begin{tabular}{|c|c|c|c|c|c|}
\hline $\begin{array}{c}\text { Control } \\
\text { Strategy }\end{array}$ & Uncontrolled & Passive-Off & Passive-On & $\begin{array}{c}\text { Clipped-Optimal } \\
\text { Control } \\
\text { (MR Damper) }\end{array}$ & $\begin{array}{c}\text { Ideal Active } \\
\text { Control }\end{array}$ \\
\hline \hline$x_{i}$ & 0.538 & 0.211 & 0.076 & 0.114 & 0.108 \\
$(\mathrm{~cm})$ & 0.820 & 0.357 & 0.196 & 0.185 & 0.154 \\
& 0.962 & 0.455 & 0.306 & 0.212 & 0.236 \\
\hline$d_{i}$ & 0.538 & 0.211 & 0.076 & 0.114 & 0.108 \\
$(\mathrm{~cm})$ & 0.319 & 0.153 & 0.158 & 0.090 & 0.132 \\
& 0.201 & 0.103 & 0.110 & 0.101 & 0.082 \\
$\ddot{x}_{a i}$ & 856 & 420 & 281 & 696 & 445 \\
$\left(\mathrm{~cm} / \mathrm{sec}^{2}\right)$ & 1030 & 480 & 494 & 739 & 393 \\
\hline$f$ & 1400 & 717 & 767 & 703 & 569 \\
\hline$(\mathrm{N})$ & - & 258 & 979 & 941 & 941 \\
\hline
\end{tabular}

sive-off system reduces the maximum relative displacement of the third floor by $52.7 \%$ of the uncontrolled values, and the passive-on system achieves a $68.1 \%$ reduction. Both passive systems reduce the upper story absolute accelerations and interstory displacements by approximately $50 \%$. However, as compared to the passive-off case, notice that the passive-on controller increases both the absolute accelerations and the interstory displacements of the upper floors. Apparently, choosing a passive device that produces the largest damping forces may not always be the most effective approach to protective system design. 
Using the control law in Eq. (12), the closed loop semi-active system is simulated. Because the MR damper has the ability to dynamically modify its properties, the performance of the system employing a clipped-optimal controller (i.e., semi-actively controlled) surpasses that of both passive systems. The time responses for the third floor relative displacement and the third floor absolute acceleration are shown in Fig. 10. Notice that the MR damper is able to reduce the structural responses, even during the first few cycles of the response. The peak structural responses to the El Centro earthquake are given in Table 2. The clipped-optimal controller reduces the peak third floor relative displacement by an additional $30.7 \%$ and reduces the maximum peak interstory displacement by an additional $27.8 \%$, as compared to the best passive responses. Notice that these performance gains are achieved by the semi-active controller while requiring smaller control forces than are required in the passive-on case. In addition, the semi-active controller reduces the maximum peak absolute floor acceleration more than the passive-on case, although not quite as well as for the passive-off case.

Insight into how the semi-active system achieves improved performance over the passive system is seen by examining Fig. 11, which compares the control forces produced by the MR damper for the strong motion portion of the El Centro earthquake operating in both the semi-active and passive-on modes. A scaled version of the commanded voltage to the MR damper is superimposed on the figure. The ability of the MR damper to quickly respond to changes in the command-
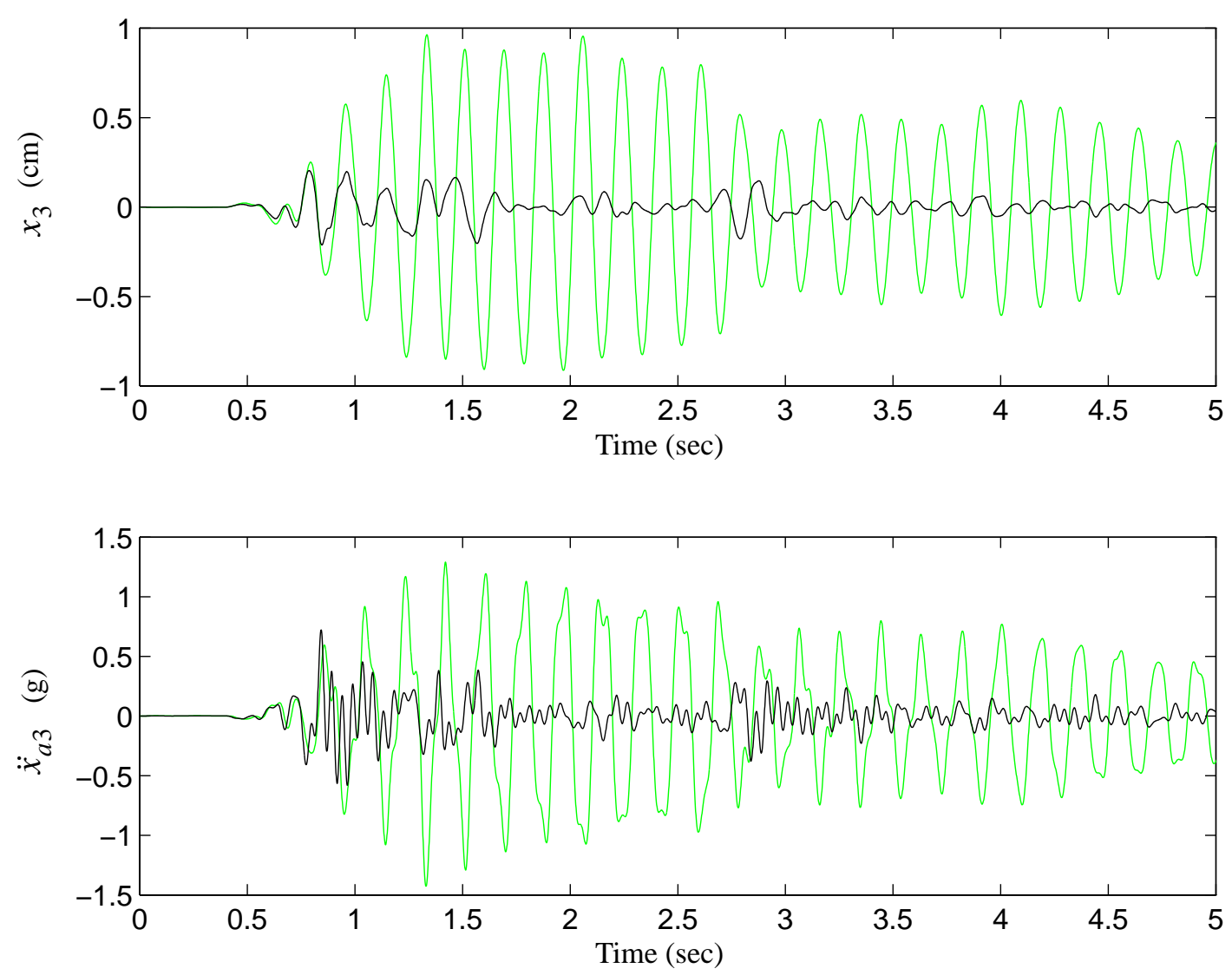

Figure 10. Structural Responses of Uncontrolled and ClippedOptimal Systems due to the El Centro Earthquake. 


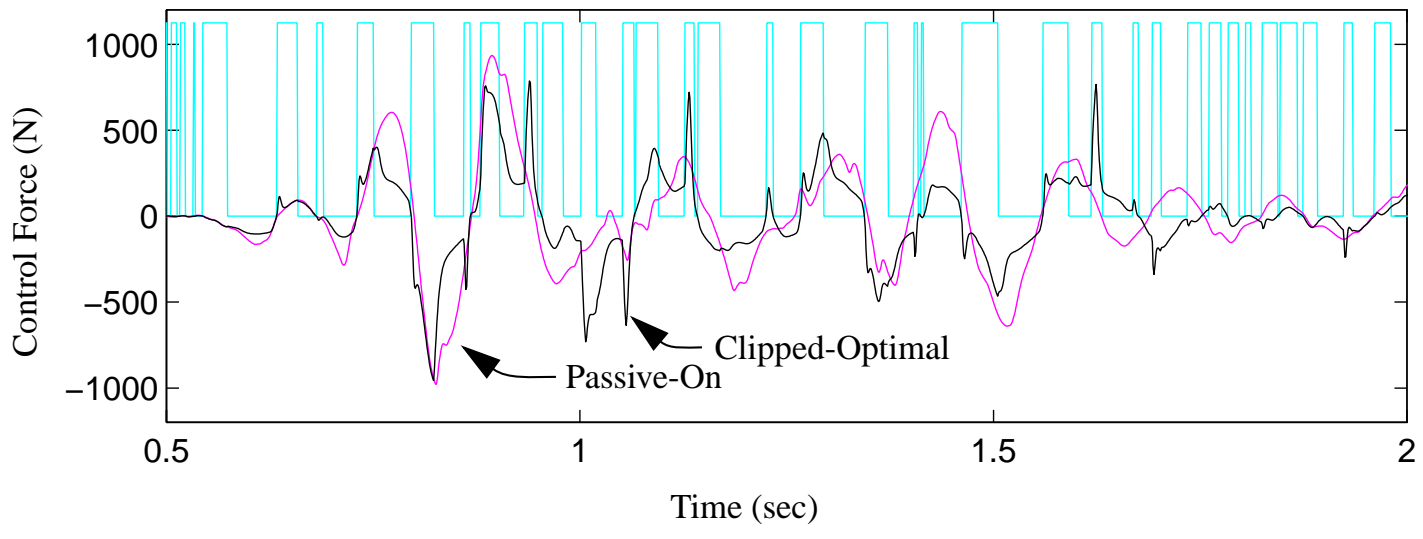

Figure 11. Command Signal and Control Force Applied in the Clipped-Optimal Case, and Reaction Force for the Passive-On Case due to the El Centro Earthquake.

ed voltage are clearly seen here. The peak in the structural responses occurs at approximately 0.8 seconds. At this time the semi-active force increases and then sharply rolls off much faster than the force produced in the passive-on mode. Interestingly, the forces applied by the MR damper operating in semi-active mode are often smaller than those corresponding to the damper operating in the passive-on mode, again indicating that larger damping forces do not always produce better results.

As a final evaluation study, an assessment is made of the ability of the MR damper to achieve the performance of a comparable fully active control system. To this end, the active controller is assumed to be ideal, in that actuator/sensor dynamics are not considered. In reality, actuator/sensor dynamics often limit achievable performance [12]. Moreover, the forces generated by an actuator can be highly dependent on the corresponding response of the structure, particularly for lightly damped system. In this study, the actuator used to generate the active control forces is considered to be nondynamic and capable of generating the required control forces instantaneously; no interaction is allowed between the structure and the actuator. With these assumptions, the active control case considered herein is designated an ideal controller and represents an upper bound on active control system performance for an appropriately sized actuator.

To have a basis for comparison of the active and semi-active control systems, a linear active controller is designed such that the peak control force is the same as that of the semi-active controller. Thus, the same capacity actuator would be required to implement either control strategy. An $H_{2}$ /LQG optimal active controller is designed by weighting both the third floor absolute acceleration and the third floor relative displacement.

The peak responses for the actively controlled structure are provided in Table 2 . The ideal active control system is also very effective in reducing the structural responses due to the El Centro earthquake, particularly the accelerations. Interesting, the peak third floor relative displacement was $10 \%$ smaller for the clipped optimal controller than for the active system. The maximum of the peak interstory displacements is also $15 \%$ smaller with the clipped-optimal controller than with the active control. This result is quite remarkable given that the MR damper uses only a small fraction of the power required to operate the active control system. This result may be attributed in part to the fact that semi-active devices are inherently stable, allowing high authority control strategies to be effectively designed and implemented. 


\section{Conclusions}

The performance of a semi-active control system based on newly developed magnetorheological (MR) fluid dampers has been studied. A recently reported model for the MR damper was presented which is capable of predicting the response of the MR damper over a wide range of loading conditions and command voltages, and a clipped-optimal controller was proposed for control implementation. In this approach, a linear optimal controller was designed and combined with a force feedback loop to adjust the command voltage of the MR damper to approximate the optimal force level. One of the attractive features of this control strategy is the fact that the feedback for the controller is based readily obtainable acceleration measurements, thus making them quite implementable. In addition, the proposed control design does not require a model for the MR damper.

The effectiveness of the MR damper using the proposed clipped-optimal control law has been demonstrated through numerical example. Excellent results were obtained when this strategy was applied to control a model of a seismically excited three-story scaled building model. Because the semi-active system has the ability to vary its properties to more effectively control the structure, the clipped optimal controller performed better than both the passive-off and passive-on control systems. A comparably designed ideal active control system was also considered. The performance of the semi-active control system employing the MR damper was found to be modestly better in reducing peak displacements than that of the linear active controller, indicating that the semi-active control system is capable of not only approaching, but surpassing, the performance of linear active control system, while only requiring a small fraction of the power that is required by the active controller. Similar results have been obtained experimentally $[11,16]$. Additionally, full-scale MR dampers have been designed [8] and will be tested at the University of Notre Dame in the near future.

Finally, note that the algorithms that explicitly incorporate actuator dynamics and controlstructure interaction into the control design process may offer additional controlled performance gains [12]. Efforts are currently underway to investigate this possibility.

\section{Acknowledgment}

This research is supported in part by National Science Foundation Grant Nos. CMS 9301584 and CMS 95-00301. In addition, the authors from Notre Dame would like to express their appreciation to the Lord Corporation of Cary, North Carolina for providing the prototype magnetorheological damper. In particular, the encouragement and advice of Mr. Thomas Loftus is gratefully acknowledged.

\section{References}

[1] Akbay, Z. and Aktan, H.M., "Actively Regulated Friction Slip Devices." Proc. 6th Canadian Conf. on Earthquake Engrg., pp. 367-374, 1991.

[2] Burton, S. A., Makris, N., Konstantopoulos, I. and Antsaklis, P. J., "Modeling the Response of an Electrorheological Damper: Phenomenology and Emulation." Journal of Engineering Mechanics, ASCE (in press). 
[3] Carlson, J.D., "The Promise of Controllable Fluids." Proc. of Actuator 94 (H. Borgmann and K. Lenz, Eds.), AXON Technologie Consult GmbH, pp. 266-270, 1994.

[4] Carlson, J.D. and Weiss, K.D., “A Growing Attraction to Magnetic Fluids.” Machine Design, August, pp. 61-64, 1994.

[5] Carlson, J.D., Catanzarite, D.M. and St. Clair, K.A., "Commercial Magneto-Rheological Fluid Devices." Proc. 5th Int. Conf. on ER Fluids, MR Fluids and Associated Tech., U. Sheffield, UK, 1995.

[6] Carlson, J.D. and Chrzan, M.J., "Magnetorheological Fluid Dampers." U.S. Patent \#5,277,281, 1994.

[7] Carlson, J.D. Chrzan, M.J., and James, F.O., "Magnetorheological Fluid Devices." U.S. Patent \#5,398,917, 1995.

[8] Carlson, J.D. and Spencer Jr., B.F., "Magneto-Rheological Fluid Dampers for Semi-Active Seismic Control," Proceedings, 3rd International Conference on Motion and Vibr. Control, Chiba, Japan, September, 1996, Vol. III, pp. 35-40.

[9] Constantinou, M.C. and Symans, M.D., "Semi-Active Fluid Viscous Dampers for Seismic Response Control." Proc. 1st World Conf. on Struct. Control, Pasadena, CA, FA4:3-12, 1994.

[10] Dowdell, D.J and Cherry, S., "Semi-Active Friction Dampers for Seismic Response Control of Structures." Proc. 5th US Nat. Conf. on Earthquake Engrg., 1:819-828, 1994.

[11] Dyke, S.J., "Acceleration Feedback Control Strategies for Active and Semi-Active Systems: Modeling, Algorithm Development and Experimental Verification.” Ph.D. Dissertation, Department of Civil Engineering and Geological Sciences, University of Notre Dame, Notre Dame, Indiana, 1996.

[12] Dyke, S.J., Spencer Jr., B.F., Quast, P., and Sain, M.K., "The Role of Control-Structure Interaction in Protective System Design.” J. of Engrg. Mech, ASCE, Vol. 121, No. 2, pp. 322-38, 1995.

[13] Dyke, S.J., Spencer Jr., B.F., Quast, P., Kaspari, Jr., D.C., and Sain, M.K., "Implementation of an Active Mass Driver Using Acceleration Feedback Control." Microcomputers in Civil Engineering: Special Issue on Active and Hybrid Structural Control, Vol. 11, 1996, pp. 305323.

[14] Dyke, S.J., Spencer Jr., B.F., Quast, P., Sain, M.K., Kaspari Jr., D.C. and Soong, T.T., “Acceleration Feedback Control of MDOF Structures." J. of Engrg. Mech, ASCE, Vol. 122, No. 9, 1996, pp. 1-12.

[15] Dyke, S.J., Spencer Jr., B.F., Sain, M.K. and Carlson, J.D., "Seismic Response Reduction Using Magnetorheological Dampers," Proceedings of the IFAC World Congress, San Francisco, California, June 30-July 5, 1996, Vol. L, pp. 145-150. 
[16] Dyke, S.J., Spencer Jr., B.F., Sain, M.K. and Carlson, J.D., "Experimental Verification of Semi-Active Structural Control Strategies Using Acceleration Feedback," Proc., 3rd Int. Conf. on Motion and Vibr. Control, Chiba, Japan (1996), Vol. III, pp. 291-296.

[17] Ehrgott, R.C. and Masri, S.F., "Modelling of Oscillatory Dynamic Behavior of Electrorheological Materials in Shear." Smart Materials and Struct., 4:275-285, 1992.

[18] Ehrgott, R.C. and Masri, S.F., "Structural Control Applications of an Electrorheological Device." Proc. Int. Workshop on Struct. Control, USC Pub. No. CE-9311, pp. 115-129, 1994.

[19] Feng, Q. and Shinozuka, M., "Use of a Variable Damper for Hybrid Control of Bridge Response under Earthquake." Proc. U.S. Nat. Workshop on Struct. Control Res. USC Publication No. CE-9013, pp. 107-112, 1990.

[20] Fujino, Y., Soong, T.T. and Spencer Jr., B.F., "Structural Control: Basic Concepts and Applications." Proc. ASCE Struct. Cong., Chicago, Illinois, April 15-18, 1996, pp. 1277-1287.

[21] Gavin, H.P., Hose, Y.D., and Hanson, R.D., "Design and Control of Electrorheological Dampers." Proc. 1st World Conf. on Struct. Control, WP3:83-92, 1994.

[22] Housner, G.W. and Masri, S.F. (Eds.), Proc. U.S. National Workshop on Struct. Control Res., USC Publications No. M9013, University of Southern California, 1990.

[23] Housner, G.W. and Masri, S.F. (Eds.), Proc. Int. Workshop on Struct. Control, USC Publication No. CE-9311, Univ. of Southern California, 1993.

[24] Housner, G.W., Masri, S.F. and Chassiakos, A.G. (Eds.), Proc. 1st World Conf. on Struct. Control, Pasadena, CA, 1994.

[25] Ivers, D.E. and Miller, L.R., "Experimental Comparison of Passive, Semi-Active On/Off, and Semi-Active Continuous Suspensions." SAE Technical Paper Series No. 892484, 1989.

[26] Kawashima, K., Unjoh, S. and Shimizu, K., "Experiments on Dynamics Characteristics of Variable Damper." Proc. of the Japan Nat. Symp. on Struct. Resp. Control, Tokyo, Japan, $121,1992$.

[27] Kobori, T., Takahashi, M., Nasu, T., Niwa, N. and Ogasawara, K., "Seismic Response Controlled Structure with Active Variable Stiffness System." Earthquake Engrg. and Struct. Dyn., 22:925-941, 1993.

[28] Kobori, T., "Future Direction on Research and Development of Seismic-Response-Controlled Structure." Proc. 1st World Conf. on Struct. Control, Panel:19-31, 1994.

[29] Kurata, N., Kobori, T., Takahashi, M. Niwa, N. and Kurino, H. "Shaking Table Experiments of Active Variable Damping System." Proc. 1st World Conf. on Struct. Control, Pasadena, CA, TP2:108-107, 1994. 
[30] Makris, N., Hill, D., Burton, S. and Jordan, M., "Electrorheological Fluid Dampers for Seismic Protection of Structures." Proc. SPIE Conf. on Smart Struct. and Materials (I. Chopra, Ed.), San Diego, California, pp. 184-194, 1995.

[31] MATLAB, The Math Works, Inc., Natick, Massachusetts, 1994.

[32] McClamroch, N.H. and Gavin, H.P., "Closed Loop Structural Control Using Electrorheological Dampers." Proc. American Control Conf., Seattle, Washington, pp. 4173-4177, 1995.

[33] Miller, L.R., "Tuning Passive, Semi-Active, and Fully Active Suspensions.” IEEE, Proceedings of the Conference on Decision and Control, Paper No. 88CH25312/99/000-2047, 1988.

[34] Mizuno, T., Kobori, T., Hirai, J., Matsunaga, Y. and Niwa, N., "Development of Adjustable Hydraulic Dampers for Seismic Response Control of Large Structure." ASME PVP Conf., 229:163-170, 1992.

[35] Patten, W.N., He, Q., Kuo, C.C. Liu, L. and Sack, R.L., "Suppression of Vehicle Induced Bridge Vibration via Hydraulic Semi-Active Vibration Dampers (SAVD)." Proc. 1st World Conf. on Struct. Control, Vol 3. FA1:30-38, 1994.

[36] Sack, R.L., Kuo, C.C., Wu, H.C., Liu, L. and Patten, W.N., "Seismic Motion Control via Semiactive Hydraulic Actuators." Proc. U.S. 5th Nat. Conf. on Earthquake Engrg., Chicago, Illinois, 2:311-320, 1994.

[37] Shames, I.H. and Cozzarelli, F.A. Elastic and Inelastic Stress Analysis, Prentice Hall, Englewood Cliffs, New Jersey, 1992.

[38] Shinozuka, M., Constantinou, M.C. and Ghanem, R., "Passive and Active Fluid Dampers in Structural Applications." Proc. U.S./China/Japan Workshop on Struct. Control, Shanghai, China, pp. 507-516, 1992.

[39] Soong, T.T. Active Structural Control: Theory and Practice, Longman Scientific and Technical, Essex, England, 1990.

[40] Spencer Jr., B.F., Suhardjo, J. and Sain, M.K., "Frequency Domain Optimal Control Strategies for Aseismic Protection." J. of Engrg. Mech, ASCE, Vol. 120, No. 1, pp. 135-59.

[41] Spencer Jr., B.F., Dyke, S.J. and Sain, M.K., "Experimental Verification of Acceleration Feedback Control Strategies for Seismic Protection," Proc. of the Japan Soc. of Civil Engrg. 3 rd Colloquium on Vib. Control of Structures, Tokyo, Japan, August 7-8, 1995, Part A, pp. 259-265, 1995.

[42] Spencer Jr., B.F., Dyke, S.J., Sain, M.K. and Carlson, J.D., "Phenomenological Model of a Magnetorheological Damper.” J. Engrg. Mech., ASCE, 1996 (in press).

[43] Spencer Jr., B.F., "Recent Trends in Vibration Control in the U.S.A.," Proc., 3rd Int. Conf. on Motion and Vibr. Control, Chiba, Japan (1996), Vol. II, pp. K1-K6. 
[44] Tseng, H.E. and Hedrick, J.K., "Semi-Active Control Laws-Optimal and Sub-Optimal." Vehicle System Dynamics, Vol. 23, pp. 545-569, 1994.

[45] Wen, Y.K., "Method of Random Vibration of Hysteretic Systems." J. of Engrg. Mech. Div., ASCE, Vol. 102, No. EM2, pp. 249-263, 1976. 